\title{
EDUCAÇÃO PERMANENTE EM SAÚDE SEGUNDO OS PROFISSIONAIS DA GESTÃO DE RECIFE, PERNAMBUCO
}

\author{
CONTINUING EDUCATION IN HEALTH ACCORDING TO MANAGEMENT PROFESSIONALS FROM \\ RECIFE, PERNAMBUCO
}

\author{
EDUCACIÓN PERMANENTE EN SALUD SEGÚN LOS PROFESIONALES DE LA GESTIÓN DE \\ RECIFE, PERNAMBUCO
}

\author{
Sayonara Arruda Vieira Lima ${ }^{1}$ \\ Paulette Cavalcanti Albuquerque ${ }^{2}$ \\ Leandro David Wenceslau ${ }^{3}$
}

Resumo Este artigo discute o que pensam os profissionais da gestão sobre os processos de educação permanente em saúde no município de Recife, Pernambuco, descrevendo as ações e relacionando-as com os conceitos de educação permanente ou continuada. Originou-se de um estudo de caso, que utilizou entrevista semiestruturada com sete gestores e gerentes. A análise de conteúdo foi o método escolhido para tratamento dos dados. A educação permanente em saúde tem sido utilizada como ferramenta para pôr em prática novos dispositivos de trabalho na atenção primária à saúde. Os resultados apontam para seu uso pela gestão como ferramenta de mudança do processo de trabalho. Alguns setores da Secretaria Municipal de Saúde de Recife se apropriaram mais adequadamente do conceito de educação permanente em saúde, enquanto outros ainda a entendem como sendo igual à educação continuada. As ações surgiram das dificuldades encontradas no trabalho, a partir do que a gestão definiu como importante para a qualificação dos trabalhadores e do que as universidades perceberam como demanda para qualificação profissional. Alguns dispositivos citados foram: o apoio matricial, o apoio institucional e o projeto terapêutico singular. As dificuldades para o aperfeiçoamento das ações foram a fragmentação das ações e a pouca priorização da educação permanente em saúde por alguns profissionais da gestão.

Palavras-chave educação permanente em saúde; gestão; atenção primária à saúde.
Abstract This article discusses what management professionals think about the continuing health education processes in the city of Recife, state of Pernambuco (Northeast Brazil), describing the actions and relating them to the concepts of permanent or continuing education. It originated from a case study that used semi-structured interviews made with seven managers. Content analysis was the method chosen to process the data. Permanent health education has been used as a tool to implement new work devices in primary health care. Results point to its use by management as a tool to change the working process. A few departments of the Recife Municipal Health Secretariat appropriated themselves more properly of the permanent health education concept, while others see it as equal to continuing education. The actions arose from difficulties at work, from what management has defined as important to train workers, and from what the universities have noted as demands for professional qualification. A few devices cited were the matrix support, institutional support, and the unique therapeutic project. The difficulties faced to improve the actions were fragmentation and the lack of prioritization of continuing health education by a few management professionals.

Keywords continuing health education; management; primary health care. 


\section{Introdução}

No Brasil, a criação do Sistema Único de Saúde (SUS) já provocou profundas mudanças no acesso à saúde, mas ainda não é o bastante. Para que novas modificações ocorram, é preciso haver também alterações profundas na formação e no desenvolvimento dos profissionais da área. Com o intuito de que isso aconteça, “o Ministério da Saúde propôs a educação permanente como estratégia de transformação das práticas de formação, de atenção, de gestão, de formulação de políticas, de participação popular e do controle social no setor da Saúde" (Brasil, 2005, p. 12). A educação permanente pode ser entendida como aprendizagem-trabalho, ou seja, acontece no cotidiano das pessoas e das organizações. Ela é feita a partir dos problemas enfrentados na realidade e leva em consideração os conhecimentos e as experiências que as pessoas têm (Brasil, 2005).

Um dos pilares para a sustentação do SUS é a formação dos profissionais que trabalham no sistema. Em 2003, para suprir essa necessidade de profissionais capacitados para qualificar as ações de saúde, o Ministério da Saúde lançou a Política de Formação e Desenvolvimento para o SUS, baseada na proposta de educação permanente (Brasil, 2005). Em 2007, é publicada uma portaria com o objetivo de normatização para a organização dos processos de gestão da educação na saúde, nas diferentes esferas (Brasil, 2009a).

Segundo Ceccim (2005a, p. 175), a educação permanente em saúde (EPS) “é uma estética pedagógica para a experiência da problematização e da invenção de problemas". No setor saúde, esta estética é condição para o desenvolvimento de uma inteligência da escuta, do cuidado, do tratamento, isto é, uma produção em ato das aprendizagens relativas à intervenção ou interferência no andar da vida individual e coletiva.

Para mudar as práticas de saúde dos profissionais, principalmente os que já se encontram nos serviços, a EPS foi proposta como uma forma de excelência para a qualificação profissional. Ceccim (2005b) define o termo EPS como um processo pedagógico que coloca o cotidiano do trabalho - ou da formação - em saúde em análise. Este autor ainda pontua que essa forma educativa é permeabilizada pelas relações concretas que operam realidades e que possibilitam construir espaços coletivos para a reflexão e a avaliação de sentido dos atos produzidos no cotidiano.

Segundo Merhy (2005), todo processo que esteja comprometido com a educação permanente precisa ter a força de gerar no trabalhador, no seu cotidiano de produção do cuidado em saúde, transformações da sua prática, o que implicaria a capacidade de problematizar a si mesmo no agir.

A EPS parte do pressuposto da aprendizagem significativa, em que aprender e ensinar devem integrar a prática diária dos profissionais de saúde, pois, por meio dela, estes refletem sobre as diversas realidades e os 
modelos de atenção em saúde em que estão inseridos, com o intuito de identificar as situações-problema (Stroschein e Zocche, 2012).

De acordo com Stroschein e Zocche (2012), quando a reflexão das práticas do trabalho em equipe nos serviços de saúde permanece na condição de segundo plano ou nem acontece, ou seja, a educação permanente não é contemplada, há espaço para a reprodução de práticas de cuidado e formas de pensar individuais engessadas.

Para Ceccim e Feuerwerker (2004), uma proposta de ação estratégica para transformar a organização dos serviços e dos processos formativos implicaria trabalho articulado entre os sistemas de saúde (em suas várias esferas de gestão) e as instituições de ensino. Assim, colocaria em evidência a formação para a área da saúde como construção da educação em serviço ou da educação permanente em saúde, promovendo a agregação entre desenvolvimento individual e institucional, entre serviços e gestão setorial e entre atenção à saúde e controle social.

Para Peduzzi e colaboradores (2009), a EPS está centrada no exercício cotidiano do processo de trabalho, na valorização do trabalho como fonte de conhecimento, na articulação entre atenção à saúde, gestão e controle social, voltada à multiprofissionalidade e à interdisciplinaridade, com estratégias de ensino contextualizadas e participativas. Já a educação continuada (EC) é voltada para a concepção de educação como transmissão de conhecimento e para a valorização da ciência como fonte do conhecimento. Tende a ser pontual, fragmentada e construída de forma não articulada à gestão, à atenção e ao controle social, com enfoque nas categorias profissionais e no conhecimento técnico-científico de cada área, com ênfase em cursos e treinamentos construídos com base no diagnóstico de necessidades das categorias.

Desde 1994, o Ministério da Saúde prioriza a atenção primária à saúde, com a criação do Programa de Saúde da Família (PSF). Entretanto, em 1998, este programa passa a ser chamado de Estratégia Saúde da Família, por ser considerado estratégia estruturante dos sistemas municipais de saúde, com potencial para provocar importante reordenamento do modelo de atenção vigente. Nesse sentido, a operacionalização da Estratégia Saúde da Família não se apresenta como uma tarefa simples, o que sugere a necessidade de se compor uma equipe com capacidade de articular as diversas políticas sociais e recursos, de maneira a contribuir para a identificação das causalidades e das multiplicidades de fatores que incidem na qualidade de vida da população (Scherer, Marino e Ramos, 2005).

De acordo com Corbo, Morosini e Pontes (2007), o PSF incorpora as noções de integralidade e universalidade da assistência, equidade, resolutividade e humanização do atendimento e estímulo à participação comunitária, com o objetivo de corrigir as diversas distorções que os modelos de assistência à saúde apresentaram no decorrer dos anos. Em 2011, com a 
publicação de uma portaria com a revisão da Política Nacional de Atenção Básica, permaneceu inclusa, como um de seus fundamentos, a valorização dos profissionais de saúde por meio do estímulo e do acompanhamento constante de sua formação e capacitação por meio da EPS (Brasil, 2011a).

\section{A educação permanente em Recife}

No período de 2009 a 2012, a Secretaria Municipal de Saúde de Recife estruturou uma prática baseada em um novo modelo de saúde, que inclui como estratégia de qualificação do trabalho a educação. Para Silva Jr. e Alves (2007), o modelo assistencial diz respeito ao modo como são organizadas, em uma dada sociedade, as ações de atenção à saúde, envolvendo os aspectos tecnológicos e assistenciais. Ou seja, é uma forma de organização e articulação entre os diversos recursos físicos, tecnológicos e humanos disponíveis para enfrentar e resolver os problemas de saúde de uma coletividade.

O modelo adotado, nesse período, foi chamado 'Recife, em defesa da vida'. Tem como uma das diretrizes analisar o cotidiano dos serviços e as práticas de saúde com o objetivo da melhoria do cuidado e responsabilização ante o usuário, com ampliação das práticas clínicas, qualificação do trabalho em equipe, cogestão com os trabalhadores e valorização dos espaços coletivos. Segundo Coelho (2008), o modelo 'Em defesa da vida' merece atenção pela ênfase dada na reforma da atividade clínica, no processo de trabalho do conjunto de profissionais da saúde e na mudança nas relações entre gestão e trabalhadores e entre estes e os usuários dos serviços.

Com a intenção de promover mudanças nas práticas de saúde do município, melhorando o atendimento nas unidades da atenção, a gestão escolheu a estratégia da EPS para estimular o debate entre os profissionais da assistência e, conforme as necessidades do trabalho, escolher como podem ser resolvidas as dificuldades. Para pôr em prática a EPS, a gestão coloca em debate as dificuldades do trabalhador em lidar com problemas na atenção aos usuários. Segundo Campos (1999, p. 394), “dispositivos são artifícios que se introduzem com o objetivo de instaurar algum processo novo - implantação de programas assistenciais, modificar traços da cultura institucional, ou para reforçar ou alterar valores". Em ocasiões em que se almejam mudanças, ou mesmo o reforço de algum comportamento, costuma-se utilizar dispositivos para intervir na realidade cotidiana dos serviços.

De acordo com Coêlho e Couto (2009), com a implantação do modelo 'Recife em defesa da vida', houve a oferta de determinados arranjos e dispositivos institucionais na Secretaria Municipal de Saúde de Recife, dentre os quais se destacam a definição do apoio matricial das especialidades, 
aproximando-as da atenção primária, o fortalecimento da clínica compartilhada e o apoio institucional às equipes.

Esse novo modelo proposto na capital pernambucana tem a EPS como ferramenta de mudança, portanto desenvolveu-se uma pesquisa com o objetivo de discutir o que pensam os gestores sobre os processos de educação permanente no município de Recife, verificando se as ações são de educação permanente ou de educação continuada, como as ações foram organizadas e quais foram os dispositivos citados.

\section{Desenvolvimento da pesquisa}

\section{População de estudo e coleta de dados}

Este artigo divulga os resultados de um estudo descritivo exploratório, 4 com abordagem qualitativa, realizado por meio de entrevista semiestruturada. Foram escolhidos para a realização da pesquisa atores-chave que trabalham na gestão da Secretaria Municipal de Saúde de Recife: um representante da atenção primária (AP), um da vigilância em saúde (VIG), dois da gestão do trabalho (GT), um do planejamento (Plan) e dois da coordenação de políticas (Coord), num total de sete entrevistas. Como critério de inclusão, exigiu-se que os entrevistados estivessem, de alguma forma, envolvidos no desenvolvimento de ações de educação permanente no município.

Os entrevistados foram identificados de acordo com a grande área de atuação em que se encontram inseridos no serviço, a fim de assegurar o sigilo de sua identidade, mas também permitir ao leitor o entendimento de alguns posicionamentos. O trabalho de campo ocorreu no período de dezembro de 2010 a janeiro de 2011. As entrevistas foram feitas no próprio ambiente de trabalho dos entrevistados, baseadas em um roteiro de perguntas que questionavam como estavam organizadas as atividades de educação permanente, como as atividades eram escolhidas e como os diversos setores da secretaria de saúde interagiam para a organização das atividades. As entrevistas foram gravadas e depois transcritas, no mesmo período já citado.

Para a análise dos dados, tomou-se como referência a análise de conteúdo, segundo Minayo (2010). A autora destaca como importante nessa técnica de pesquisa o fato de permitir tornar replicáveis e válidas inferências sobre dados de um determinado contexto, por meio de procedimentos especializados e específicos. A modalidade de análise do conteúdo escolhida foi a análise temática, que de acordo com Minayo (2010) consiste em descobrir os núcleos de sentido que constituem uma comunicação, cuja frequência signifique algo para o objeto analisado. 
Os grandes temas que emergiram da análise foram: a definição de educação permanente, os dispositivos para a prática da educação permanente, as demandas e as necessidades, as dificuldades e as potencialidades.

A pesquisa foi aprovada pelo Comitê de Ética em Pesquisa da Universidade de Pernambuco (UPE), registro n. 265/10, e autorizada pela Diretoria Geral de Gestão do Trabalho da Secretaria Municipal de Saúde de Recife.

\section{Apresentação e discussão dos resultados}

\section{Definição de educação permanente}

Ceccim e Feuerwerker (2004) afirmam que é a partir da problematização do processo e da qualidade do trabalho nos serviços de saúde que são identificadas as necessidades de qualificação. Os relatos a seguir mostram-se consoantes com o conceituado aqui:

A gente tem, a gente entende educação permanente como educação aquela feita no trabalho, pelo trabalho e para o trabalho, não é isso? (AP).

Então assim: para mim, educação permanente ela é feita dentro do processo de trabalho (GT 1).

A diretoria de atenção à saúde, ela está desenvolvendo uma estratégia de trabalho continuado de formação profissional a partir do debate da atuação do profissional na rede (Plan).

Campos e colaboradores (2006) dizem que a EPS vincula o aprendizado a elementos que façam sentido para as pessoas envolvidas, de forma que o processo de capacitação seja organizado mediante a problematização do processo de trabalho. É a aprendizagem no trabalho. Outras falas fazem referência ao conceito de EPS, explicando as possíveis maneiras de se colocar em prática no dia a dia:

Então é nesse sentido, a partir da troca, desse fazer junto, independente de estar no atendimento compartilhado, de estar fazendo um grupo educativo ou terapêutico, estar fazendo uma visita domiciliar, estar fazendo qualquer intervenção junto, uma discussão de caso, que é o mais comum, o apoiador matricial e o profissional de referência estão interagindo, trocando experiências, e esse é também um momento de educação permanente (Coord 2). 
Mas entendendo que os espaços instituídos de diálogo entre gestão e trabalhador, dentro dos fóruns, dentro das reuniões sistemáticas, a partir do apoio do Nasf, são espaços da educação permanente que podem ser potencializados na atenção básica (Plan).

Essas falas reiteram a concepção de educação permanente em saúde, apontando como acontece na prática a EPS e em que espaços ou cenários do trabalho em saúde.

Para Campos e colaboradores (2006), a atualização técnico-científica é apenas um dos pontos de mudança das práticas, e não o foco central na EPS que rompe com a lógica centralizada e verticalizada da oferta de cursos padronizados, em contraposição ao conceito de EC, em que o conhecimento define as práticas. Nesse mesmo sentido, Montanha e Peduzzi (2010) criticam a concepção de EC porque esta é proposta para o preparo de determinada função e melhora do desempenho do trabalhador com ênfase em treinamentos, palestras e cursos para o aperfeiçoamento técnico-científico, não se constituindo em espaço de reflexão e crítica das práticas de trabalho.

Apesar da escolha da EPS como ferramenta de mudança na vivência do trabalho, que tem como ideia utilizar a educação para os profissionais de saúde pensarem o cotidiano e os problemas enfrentados, a gestão ainda mantém paralelamente o modelo de usar os cursos técnicos pontuais como uma forma de capacitação profissional, como a seguinte fala refere:

Então a gente na verdade tem tido esses dois eixos de atuação: as capacitações pontuais definidas de curto período realizadas pelas áreas técnicas, que permanecem acontecendo, e a estratégia de formação continuada da atenção básica, que se baseia em reuniões periódicas com os profissionais da rede e em discussão de casos entre profissionais da rede especializada e da rede de atenção básica (Plan).

Em outra fala, esses cursos pontuais são apresentados como ações de educação permanente, podendo refletir a pouca aproximação teórica do entrevistado com esse conceito ou uma utilização indiscriminada dos dois conceitos (EPS e EC):

E tem a forma tradicional, que é quando você organiza aulas, as aulas presenciais, né?, e atualizações, seminários, simpósios, tudo isso são processos de educação permanente (Coord 1).

Note-se que as duas últimas falas podem mostrar a existência de duas formas de conduzir o processo de aprendizagem na gestão: com a prática da EPS e da EC. 
A metodologia de cursos pontuais geralmente não estimula a autonomia do trabalhador, importante para a tomada de decisões, no que concerne não só a posturas diferentes do que estabelecem os protocolos técnicos dos cursos de formação como, também, ao enfrentamento da discussão com a gestão. Cecílio (2007) pontua que os gestores da saúde têm de assumir que existe um espaço de liberdade dos trabalhadores da saúde e que este, muitas vezes, pode ir no sentido contrário às propostas que os gestores consideram inovadoras e necessárias.

\section{Os dispositivos para a prática da educação permanente}

Após a análise das falas, apareceram os seguintes dispositivos como meios de pôr em prática a EPS: as reuniões dos profissionais por microrregião, o apoio matricial, o apoio institucional e o uso do projeto terapêutico singular (PTS) e da consulta compartilhada para discussão de casos clínicos.

Oliveira (2008a) diz que a aposta no apoio matricial está na troca de saberes entre equipes e profissionais em torno da busca de ofertas de ações e serviços que tenham potência para modificar positivamente os problemas de saúde, com o uso, de forma racional, de todos os recursos disponíveis. Campos e Domitti (2007) afirmam que o apoio matricial procura construir espaço para comunicação ativa e para o compartilhamento de conhecimento entre profissionais da assistência e apoiadores.

O Núcleo de Apoio à Saúde da Família (Nasf) poderia pôr em prática as ações de apoio matricial, uma vez que tem como uma de suas responsabilidades atuar na EPS. A equipe do Nasf e as equipes da saúde da família criam espaços de discussões para gestão do cuidado, como, por exemplo, reuniões e atendimentos conjuntos constituindo processo de aprendizado coletivo (Brasil, 2011b. As falas a seguir confirmam a prática do apoio matricial que ocorreu por meio da atuação do Nasf:

O Nasf, quando eu cito o Nasf como potencial de educação permanente, é porque o formato que a gente está implantando o Nasf no município, um apoio matricial no desenvolver das equipes, das ações das equipes em saúde da família baseado no fazer junto (Coord 2).

A gente está propondo exatamente assim: essas equipes do Nasf, eles atuam junto com os profissionais de saúde da família. Então eles vão fazer atendimentos compartilhados, vão estar apoiando a formação de grupos, ou fortalecendo grupos instituídos, então é muito nessa perspectiva. Então vai ser realmente educação permanente feita tête-à-tête, a partir daquela necessidade apresentada (AP). 
Um segundo dispositivo citado nas entrevistas foi o apoio institucional. Para Moura e colaboradores (2007), os apoiadores constituem-se em equipes compostas por diferentes profissionais da saúde que devem apoiar os gestores e equipes assistenciais com vários recursos, dentre eles os pedagógicos. Os encontros do apoiador com as equipes também podem ser espaços de EPS, a partir do momento em que se faz a análise da forma como as equipes realizam o trabalho. A seguinte fala se refere a esse dispositivo:

O trabalho, por exemplo, do apoio institucional, ele, no seu dia a dia, ele tá permeado pela educação permanente. Então a gente tá levando, nas equipes de saúde da família a gente tá levando, trazendo questões para a própria equipe, para discutir e analisar o seu próprio processo de trabalho (AP).

Um terceiro dispositivo foi o projeto terapêutico singular (PTS). Oliveira (2008b) afirma que o PTS é um movimento de coprodução e cogestão do processo terapêutico de indivíduos ou coletivos em situação de vulnerabilidade, que necessita de uma construção coletiva envolvendo o profissional, a equipe de saúde, os usuários e a família. Além disso, a consulta ao usuário pode ser feita de forma compartilhada, que segundo Campos e Domitti (2007) pode se dar por meio de atendimentos e intervenções conjuntas entre o especialista matricial e alguns profissionais da equipe de referência, potencializando o atendimento e dando mais resolutividade ao caso. As falas a seguir expõem o uso do dispositivo na rede:

Está se introduzindo na rede a discussão tanto do projeto terapêutico singular como da discussão de casos e da consulta conjunta entre profissionais especializados e profissionais da atenção básica, e isso é uma estratégia de prática de trabalho diferenciada, mas também é uma estratégia de formação continuada, de formação permanente (Plan).

As discussões dos projetos terapêuticos singulares também, que a gente bota toda a equipe para estar discutindo aquele caso em profundidade, assim, são dispositivos do modelo de uma forma em geral (AP).

Outro dispositivo encontrado como forma de implementação da EPS vislumbrado nas falas são as reuniões de microárea, como demonstra a passagem:

A gente tem a questão das reuniões de micro, que são espaços de cogestão, que lá também a gente está. É um espaço fortemente de educação permanente, de troca dentro das equipes, troca de experiências, de dúvidas, enfim. Então, o formato dessa reunião de micro, ela permite que a gente faça discussões [de caso clínico], 
desde discussão de caso clínico, até se tem algum protocolo (...), trocar experiência que tá acontecendo em uma unidade de saúde, como é que eles tão trabalhando, enfim (...) (AP).

Segundo Pinto (2008), é importante que os espaços coletivos existam para que as pessoas se encontrem, conversem, discutam, falem sobre seus conflitos, combinem formas de trabalhar e firmem compromissos. As reuniões de microárea são espaços que podem ser utilizados para EPS de acordo com o último relato.

\section{As demandas e as necessidades}

Para Campos e colaboradores (2006), a EPS propõe a transformação das práticas dos profissionais e da própria organização do trabalho, tomando como referência as necessidades de saúde dos usuários e das populações, da gestão setorial e do controle social. Tal assertiva também é verificada por Montanha e Peduzzi (2010), em pesquisa realizada para saber as necessidades de realização das ações de EPS. Os autores indicam a capacitação técnico-científica, as necessidades sentidas pelo supervisor da equipe, as dificuldades apontadas para lidar com os usuários e na execução do cuidado como os principais motivos para realização de ações educativas. As seguintes falas refletem visão semelhante dos profissionais aqui pesquisados com as pontuações dos autores referidos:

Então a gente vai elencando os temas que vão ser trabalhados nas reuniões de micro mensais. Essa é a forma que a gente faz através de escuta do trabalhador, das demandas e necessidades (...) (AP).

Essas atribuições foram sendo construídas a partir das referências ministeriais, a partir da realidade local e a partir da intervenção, combinação e pactuação entre equipe Nasf e equipe da saúde da família. Porque se a gente está combinando de fazer isso junto, a gente num vai chegar com oferta e vai chegar com priorização das equipes de atuação em uma certa área, em uma certa temática (Coord 2).

Então, assim, nosso objetivo hoje aqui na diretoria é a gente ter um canal de comunicação próximo, de toda a rede mesmo, dos trabalhadores da rede, para que a gente possa levantar essas necessidades de formação - de formação formal entre si, mais direta. A partir da realidade mesmo do serviço (GT 2).

Além de as demandas serem apontadas pelos trabalhadores, uma segunda forma é pelas necessidades vislumbradas pela gestão, corroborando o que Peduzzi e colaboradores (2009) afirmam: a demanda por atividades educati- 
vas origina-se, na maior parte, de forma externa ao serviço, isto é, não parte de demandas dos trabalhadores. As falas refletem o que foi pontuado pelos autores referidos:

A própria vigilância sanitária, ela já monta o curso junto com a diretoria da vigilância propriamente dita e faz o formato dela, dentro do que a gestão entende por necessidade (AP).

Quando, na vigilância, tem também sanitaristas! Então eles estão apontando o que é que a gente tem de trabalhar de imediato, em que a gente tem de atacar, como é que a gente tem que... o que é que os profissionais estão precisando na área de capacitação (Vig).

Outra forma citada para identificação de demandas foi a programação anual de saúde, que a gestão realizava como um dos instrumentos de planejamento, em que eram sistematizadas as ações realizadas durante o ano, de acordo com o plano de saúde (Brasil, 2009b). A fala de um profissional entrevistado pontua essa questão:

E a programação anual de saúde, ela é o momento em que as áreas técnicas vão definir as suas estratégias para o ano, as suas principais atividades para o ano e definir também quais são os cursos, as capacitações, os debates, as formulações que vão ser feitas ao longo do ano (Plan).

Cecílio (2007) afirma que é necessário ter o cuidado de não levar prontas, sistematizadas, categorias incrustadas em modelos ou métodos, mas construir e desconstruir conceitos no encontro com o outro, também produtor de conceitos que nem sempre são os dos gestores. Contraditoriamente a essa informação, as falas parecem relatar outra forma de identificar demandas de ações de EPS, utilizando como critérios os indicadores de saúde ou prescrições ministeriais, sem garantir o espaço do trabalhador, como se pode aferir a seguir:

A gente está puxando e trabalhando dessa forma, de acordo com os indicadores que tem sido apontados (Vig).

Em relação às coordenações das políticas, algumas dessas demandas é [sic] feita assim e outras são do próprio programa que já vem determinado pelo ministério, identificada através de indicadores que a gente tem (AP).

Por fim, outra forma verificada nas falas dos pesquisados como fonte de determinação das necessidades para EPS é a integração ensino-serviço, 
especialmente com as universidades. De acordo com Ceccim e Feuerwerker (2004), cabe ao SUS e às instituições de educação coletar, sistematizar, analisar e interpretar informações da realidade, problematizar o trabalho e as organizações de saúde e de ensino, com a construção de significados e práticas baseados na organização social, mediante participação dos gestores, formadores, usuários e estudantes. As seguintes falas abordam essa parceria:

Dessa forma, as instituições de ensino estão presentes no serviço, têm um dado de realidade, estão próximas... Então, no processo de cogestão, traz esses levantamentos e a gente vê como viabiliza essas demandas (GT 2).

Nós temos oficinas, seminários, que normalmente são feitos semestralmente com as instituições de ensino. E, como a gente já tem a territorialização da questão do ensino e serviço, então essas necessidades elas são levantadas nesses espaços (GT 2).

As falas a respeito da relação ensino-serviço e sua importância na cogestão das ações corroboram o que afirma Ceccim (2005c), que faz referência à integração entre o ensino, os serviços, a gestão setorial e o trabalho no SUS. O autor reforça que, ao mesmo tempo, essa parceria deveria reconhecer a necessidade de disputa pela atualização cotidiana das práticas, deveria inserir as instituições de ensino superior (IES) em uma construção de relações que vão desde as equipes em atuação conjunta até as práticas organizacionais.

\section{As dificuldades e as potencialidades}

Segundo Lopes e colaboradores (2007), algumas dificuldades surgem nos processos de EPS: decisões com relação à gestão do trabalho descontextualizado do planejamento da atenção em saúde, dissociação entre planejamento e educação e saúde, ausência de definição de políticas de saúde e enfoque de trabalho fragmentado por profissões.

Enfatizando o efeito negativo da fragmentação dos setores na implantação das ações de EPS, Ceccim (2005b) afirma que cada área técnica sempre parte do máximo de conhecimentos acumulados em seu núcleo de saberes e que, com base nessas referências, propõem ações programáticas, quase sempre assentadas na assistência individual ou na abordagem de vigilância à saúde. As falas a seguir exemplificam essa questão:

Ainda tá muito fragmentado, digamos assim, a gente tá precisando integrar mais (AP).

As políticas... têm as suas capacitações, suas qualificações, a partir de projetos que são elaboradas por elas, com recursos do Ministério da Saúde. Então faz toda formação já direto com os profissionais (GT 2). 
No plano municipal de saúde que está em vigência, que começou a vigência dele este ano, várias áreas, a gente na verdade perseverou numa prática que já era anterior: cada área técnica formulou sua estratégia de treinamento, a sua estratégia de capacitação profissional e de educação dos profissionais (Plan).

Outra dificuldade apontada nas falas dos pesquisados diz respeito à pouca priorização da EPS pela gestão. Tal postura reitera o que afirma Laranja (2012), sobre uma das dificuldades para o sucesso da implementação da EPS ser a falta de apoio da gestão, para que esta ganhe espaço institucional que lhe garanta sustentabilidade. A fala a seguir expõe a preocupação com a falta de priorização da política em Recife:

Porque essa questão de educação, ela não é uma coisa que tenha um retorno de imediato, não é? Então termina não sendo, tão ainda, uma coisa priorizada. Porque às vezes você faz uma discussão aqui de uma proposta, mas o retorno disso, o impacto disso... A médio e longo prazo... Então não é? Não é tão priorizada (GT 2).

Uma das potencialidades apresentadas pelos pesquisados para a realização da EPS é a integração ensino-serviço, como se verifica a seguir:

E aí pensando assim a gente tem conseguido alcançar um número bem significante [de profissionais] em relação ao PET [Programa de Educação pelo Trabalho para a Saúde], que pra gente também é uma riqueza, né? É uma troca de informações, assim... Tem profissionais que dizem que voltou [sic] a estudar. "Amei, voltei a estudar!" Tem outros que "eu não quero nem ver estudante na minha frente!" Mas aí... (GT 1).

Uma das metas que a gente vai priorizar é a questão do ensino, que isso, a questão do ensino, a gente considera como qualificação. A unidade que hoje recebe estudantes, ela tanto está formando quanto está se qualificando (GT 2).

De acordo com Lopes e colaboradores (2007), a efetividade da educação permanente em saúde como política para o SUS depende da relação entre as instituições de saúde e de educação, e da capacidade de elas desenvolverem ações descentralizadas por toda a rede de serviços.

\section{Considerações finais}

O estudo conclui que a educação permanente em saúde foi uma das ferramentas utilizadas pela gestão do município de Recife na tentativa de modificar 
o processo de trabalho e as práticas de saúde. Observou-se que os gestores da atenção básica e a gestão do trabalho demonstraram maior apropriação do conceito de EPS, enquanto gestores de outros setores, como a vigilância, ainda entendem a EPS como EC.

Identificou-se que a EPS foi realizada em Recife por meio de dispositivos como as reuniões dos profissionais por microrregião, o apoio matricial, o apoio institucional, o uso de projeto terapêutico singular e da consulta compartilhada para discussão de casos clínicos. Tais dispositivos parecem ter possibilitado a uma parte dos profissionais da atenção novas formas de realizar a clínica, de serem cogestores na realização das ações de saúde, de trabalharem em equipe, aprendendo novos conhecimentos e oferecendo melhor atenção em saúde à comunidade.

Outro ponto de destaque neste estudo foi o fato de os gestores relatarem que ações de EPS surgiram a partir das dificuldades encontradas no dia a dia do trabalho, do que a gestão acreditava que seria importante para a qualificação dos trabalhadores e para a melhoria das ações de saúde. Os depoimentos também revelaram que problemas de saúde que emergem da análise dos indicadores, das demandas ministeriais e das universidades também geraram ações de EPS.

As dificuldades citadas pelos gestores para pôr em prática as ações de EPS referiram-se à fragmentação das ações realizadas pelos diversos setores e à pouca priorização da política em Recife. A integração ensino-serviço surgiu como possibilidade de potencializar as ações de educação permanente.

Finalizando, a pesquisa identificou que a EPS podia ter sido priorizada pela gestão, que os gestores não a perceberam como política, e que também poderia ter se investido mais na compreensão do conceito de EPS por todos.

A vivência deste trabalho nos permite recomendar que o aperfeiçoamento das ações de EPS necessita ser trabalhado, com a gestão colocando a política de educação permanente em saúde como prioridade estratégica de reorientação dos serviços e garantindo a escuta dos trabalhadores para os quais essas atividades de EPS são voltadas.

\section{Colaboradores}

Sayonara Arruda Vieira Lima e Paulette Cavalcanti Albuquerque colaboraram na concepção do estudo, na análise dos resultados e na redação do artigo. Leandro David Wenceslau colaborou com a teorização e a discussão temática e na redação. 
Resumen Este artículo discute lo que piensan los profesionales de la gestión sobre los procesos de educación permanente en salud en el municipio de Recife, Pernambuco (Noreste de Brasil), describiendo las acciones y relacionándolas con los conceptos de educación permanente o continua. Se originó a partir de un estudio de caso que utilizó la entrevista semiestructurada con siete gestores y gerentes. El análisis de contenido fue el método elegido para el tratamiento de los datos. La educación permanente en salud se ha utilizado como herramienta para poner en práctica nuevos dispositivos de trabajo en atención primaria de la salud. Los resultados apuntan a su uso por la gestión como una herramienta de cambio del proceso de trabajo. Algunos sectores de la Secretaría Municipal de Salud de Recibe se apropiaron más adecuadamente del concepto de educación permanente en salud, mientras que otros todavía la ven como siendo igual a la educación continua. Las acciones surgieron de las dificultades encontradas en el trabajo, a partir de lo que la gestión definió como importante para la calificación de los trabajadores y de lo que las universidades entendieron como demanda para calificación profesional. Algunos dispositivos citados fueron: el apoyo matricial, el apoyo institucional y el proyecto terapéutico singular. Las dificultades para el mejoramiento de las acciones fueron la fragmentación de las acciones y la escasa prioridad a la educación permanente en salud por parte de algunos profesionales de la gestión.

Palabras clave educación permanente en salud; gestión; atención primaria de la salud.

\section{Notas}

1 Fundação Oswaldo Cruz, Recife, Pernambuco, Brasil.

Mestranda em Saúde Pública pelo Centro de Pesquisa Aggeu Magalhães, da Fundação

Oswaldo Cruz. <sayonaraarruda@gmail.com>

Correspondência: Rua Davino Pontual, 111, apartamento 901, Torre, CEP 50710-460, Recife, Pernambuco, Brasil.

2 Universidade de Pernambuco, Recife, Pernambuco, Brasil.

Doutora em Saúde Pública pela Fundação Oswaldo Cruz.

<paulette.cavalcanti@gmail.com>

3 Universidade Federal de Viçosa, Viçosa, Minas Gerais, Brasil.

Mestre em Educação pela Universidade Federal de Pernambuco.

<correiodoleandro@gmail.com>

4 Artigo apresentado à Faculdade de Ciências Médicas da Universidade de Pernambuco (FCM/UPE) em 2011 para conclusão da pós-graduação lato sensu, na modalidade residência, do Programa de Residência Multiprofissional em Saúde Coletiva da FCM/UPE. Pesquisa não financiada. 


\section{Referências}

BRASIL. Ministério da Saúde. Secretaria de Gestão do Trabalho e da Educação na Saúde. Departamento de Gestão da Educação na Saúde. A educação permanente entra na roda: polos de educação permanente em saúde: conceitos e caminhos a percorrer. Brasília: Ministério da Saúde, 2005. (Projetos, programas e relatórios, Série C.).

Ministério da Saúde. Secretaria de Gestão do Trabalho e da Educação na Saúde. Departamento de Gestão da Educação na Saúde. Política Nacional de Educação Permanente em Saúde. Textos Básicos de Saúde, v. 9. Brasília: Ministério da Saúde, 2009a. (Série Pactos pela Saúde 2006, Série B).

Ministério da Saúde. Sistema de planejamento do SUS: uma construção coletiva. Instrumentos básicos, v. 2. 2. ed. Brasília: Ministério da Saúde, 2009 b. (Série Cadernos de Planejamento). Disponível em: <http://bvsms. saude.gov.br/bvs/publicacoes/caderno2_ planejasus_2ed.pdf>. Acesso em: 16 mar. 2011.

Ministério da Saúde. Portaria n. 2.488, de 21 de outubro de 2011. Aprova a Política Nacional de Atenção Básica, estabelecendo a revisão de diretrizes e normas para a organização da Atenção Básica, para a Estratégia Saúde da Família (ESF) e o Programa de Agentes Comunitários de Saúde (Pacs). Disponível em: <www.brasilsus.com. br/legislacoes/gm/110154-2488.html>. Acesso em: 10 ago. 2013.

Ministério da Saúde. Saúde da Família. Núcleo de Apoio à Saúde da Família (Nasf). Disponível em: <http://dab.saude.gov. br/nasf.php>. Acesso em: 17 mar. 2011.

CAMPOS, Francisco E. et al. Os desafios atuais para a educação permanente no SUS. Cadernos RH Saúde, Brasília, v. 3, p. 39-54, 2006.

CAMPOS, Gastão W. S. Equipes de referência e apoio especializado matricial: um ensaio sobre a reorganização do trabalho em saúde.
Ciência \& Saúde Coletiva, Rio de Janeiro, v. 4, n. 2, p. 393-403, 1999.

CAMPOS, Gastão W. S.; DOMITTI, Ana C. Apoio matricial e equipe de referência: uma metodologia para gestão do trabalho interdisciplinar em saúde. Cadernos de Saúde Pública, Rio de Janeiro, v. 23, n. 2, p. 399-407, fev. 2007.

CECCIM, Ricardo B. Réplica. Interface: Comunicação, Saúde, Educação, Botucatu, v.9, n.16, p.175-177, set.2004/fev.2005a.

Educação permanente em saúde: desafio ambicioso e necessário. Interface: Comunicação, Saúde, Educação, Botucatu, v. 9, n. 16, p. 161-167, set. 2004/fev. 2005b.

Educação permanente em saúde: descentralização e disseminação de capacidade pedagógica na saúde. Ciência \& Saúde Coletiva, Rio de Janeiro, v. 10, n. 4, p. $975-$ 986, out./dez. 2005c.

CECCIM, Ricardo B.; FEUERWERKER, Laura C. M. O quadrilátero da formação para a área da saúde: ensino, gestão, atenção e controle social. Physis: Revista de Saúde Coletiva, Rio de Janeiro, v. 14, n. 1, p. 41-65, 2004.

CECÍLIO, Luiz Carlos de O. 'O trabalhador moral' na saúde: reflexões sobre um conceito. Interface: Comunicação, Saúde, Educação, Botucatu, v. 11, n. 22, p. 345-363, maio/ago. 2007.

COÊLHO, Bernadete P.; COUTO, Gustavo A. O modelo de atenção e gestão em Recife: a dupla tarefa de produção da saúde e da produção dos sujeitos no Sistema Único de Saúde. Revista Divulgação em Saúde para Debate, Rio de Janeiro, n. 44, p. 113-122, maio 2009.

COELHO, Ivan B. Formas de pensar e organizar o sistema de saúde. In: CAMPOS, Gastão W. S.; GUERRERO, André V. P. (Org.). Manual de práticas de atenção básica: saúde ampliada e compartilhada. São Paulo: Hucitec, 2008. p. 96-131. 
CORBO, Anamaria D.; MOROSINI, Márcia V. C. G.; PONTES, Ana L. M. Saúde da Família: construção de uma estratégia de atenção à saúde. In: MOROSINI, Márcia V. C. G.; CORBO, Anamaria D. (Org.) Modelos de atenção e a saúde da família. Rio de Janeiro: EPSJV/Fiocruz, 2007. p. 69-106.

LARANJA, Mirza R. A. A implementação da política nacional de educação permanente em saúde no município de São Paulo. Curso de Pós-Graduação em Gestão e Políticas Públicas, Escola de Administração de Empresas de São Paulo da Fundação Getúlio Vargas, São Paulo, 2012. Disponível em: <http:// bibliotecadigital.fgv.br/dspace/handle/10438/ 10052? show $=$ full $>$. Acesso em: 20 nov. 2012.

LOPES, Sara R. S. et al. Potencialidades da educação permanente para a transformação das práticas de saúde. Comunicação em Ciências da Saúde, Brasília, v. 18, n. 2, p. 147155, 2007.

MERHY, Emerson Elias. O desafio que a educação permanente tem em si: a pedagogia da implicação. Interface: Comunicação, Saúde, Educação, Botucatu, v. 9, n. 16, p. 172-174, set. 2004/fev. 2005.

MINAYO, Maria C. S. O desafio do conhecimento: pesquisa qualitativa em saúde. São Paulo: Hucitec, 2010.

MONTANHA, Dionize; PEDUZZI, Marina. Educação permanente em enfermagem: levantamento de necessidades e resultados esperados segundo a concepção dos trabalhadores. Revista da Escola de Enfermagem da USP, São Paulo, v. 44, n. 3, p. 597-604, 2010.

MOURA, Arthur H. et al. Análise do trabalho institucional nas equipes dos distritos sanitários e no hospital Mário Gatti, de Campinas. In: CAMPOS, Gastão Wagner Sousa. Saúde Paideia. 3. ed. São Paulo: Hucitec, 2007. p. 167-185.

OLIVEIRA, Gustavo N. Apoio matricial como tecnologia de gestão e articulação em rede. In: CAMPOS, Gastão W. S.; GUERRERO, André V. P. (Org.). Manual de práticas da atenção básica: saúde ampliada e compartilhada. São Paulo: Hucitec, 2008a. p. 273-282.

O projeto terapêutico singular. In: CAMPOS, Gastão W. S.; GUERRERO, André V. P. (Org.). Manual de práticas da atenção básica: saúde ampliada e compartilhada. São Paulo: Hucitec, 2008b. p. 283-297.

PEDUZZI, Marina et al. Atividades educativas de trabalhadores na atenção primária: concepções de educação permanente e de educação continuada em saúde presentes no cotidiano de unidades básicas de saúde em São Paulo. Interface: Comunicação, Saúde, Educação, Botucatu, v. 13, n. 30, p. 121134, jul./set. 2009.

PINTO, Carlos A. G. Diagnóstico compartilhado no trabalho das equipes de saúde da família. In: CAMPOS, Gastão W. S.; GUERRERO, André V. P. (Org.). Manual de práticas de atenção básica: saúde ampliada e compartilhada. São Paulo: Hucitec, 2008. p. 298-305.

SCHERER, Magda D. A.; MARINO, Selma R. A.; RAMOS, Flávia R. S. Rupturas e resoluções no modelo de atenção à saúde: reflexões sobre a Estratégia Saúde da Família com base nas categorias kuhnianas. Interface: Comunicação, Saúde, Educação, Botucatu, v. 9 , n. 16, p. 53-66, set. 2004/fev. 2005.

SILVA JR., Aluísio G.; ALVES, Carla A. Modelos assistenciais em saúde: desafios e perspectivas - modelos de atenção e a saúde da família. In: MOROSINI, Márcia V. C. G.; CORBO, Anamaria D. (Org.). Modelos de atenção e a saúde da família. Rio de Janeiro: EPSJV/Fiocruz, 2007. p. 27-41.

STROSCHEIN, Karina A.; ZOCCHE, Denise A. A. Educação permanente nos serviços de saúde: um estudo sobre as experiências realizadas no Brasil. Trabalho, Educação e Saúde, Rio de Janeiro, v. 9, n. 3, p. 505-519, nov. 2011 /fev. 2012.

Recebido em 10/01/2013

Aprovado em 23/07/2013 